\title{
The Attitudes of High School Students Studying in Sports High Schools in Turkey
} toward Addictive Substances

\author{
Yakup Kilic ${ }^{1}$ \\ Zeki Coskuner ${ }^{2}$ \\ ${ }_{1,2}$ PhD, Firat University, Faculty of Sports Sciences, Turkey. \\ ${ }^{2}$ Email:yakupkilic@firat.edu.tr
}

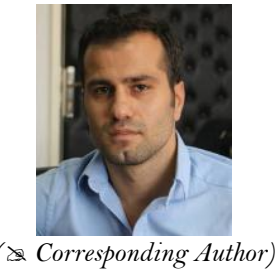

Abstract

The aim of this study is to reveal the attitudes of students, who study in sports high schools in Turkey, toward addictive substances. The study group consisted of 326 randomly selected students from Elazig, Erzincan and Malatya Sports High Schools. In order to obtain the data from the research group, the Attitude toward Addictive Substances Scale, consisting of 45 items, was used. The data obtained from 326 students were analyzed in SPSS 22 Package software. Firstly, normality analysis was performed and it was decided to perform parametric and non-parametric tests according to the results. There was a statistically significant difference in age and class variables of the students. There was no statistically significant difference between the variables of gender, monthly income of the family and educational status of the parents. As a result of the study, it was observed that male and female students' attitudes toward addiction increased as age and class levels progressed. In this context, more attention should be paid to education-oriented studies to prevent addiction. It is suggested that educational activities, such as psychological support and health programs, provided by guidance teachers and psychological counselors should be increased in number.

Keywords: Addiction, Substance abuse, Sports, Students, Turkey.

Citation | Yakup Kilic; Zeki Coskuner (2019). The Attitudes of High School Students Studying in Sports High Schools in Turkey toward Addictive Substances. Asian Journal of Education and Training, 5(4): 616-620.

History:

Received: 27 September 2019

Revised: 30 October 2019

Accepted: 4 December 2019

Published: 2 January 2020

Licensed: This work is licensed under a Creative Commons

Attribution 3.0 License (oc)

Publisher: Asian Online Journal Publishing Group
Acknowledgement: Both authors contributed to the conception and design of the study.

Funding: This study received no specific financial support.

Competing Interests: The authors declare that they have no conflict of interests.

Transparency: The authors confirm that the manuscript is an honest, accurate, and transparent account of the study was reported; that no vital features of the study have been omitted; and that any discrepancies from the study as planned have been explained.

Ethical: This study follows all ethical practices during writing.

\section{Contents}

1. Introduction

3. Results and Interpretation 618

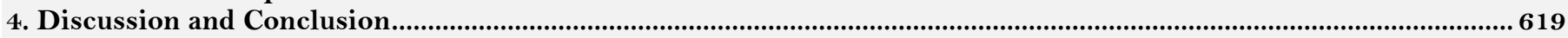

References... 


\section{Contribution of this paper to the literature}

This study contributes to the literature in terms of perceptions of substance abuse in high school students, which is one of the most critical demographic units in terms of drug use. It is believed that investigating and reporting perceptions of high school students will provide vital insight regarding substance abuse, which will enable professionals in this field to analyze, help and support high school students in a more efficient way. The study will also guide future studies on this subject via its materials, methods and results.

\section{Introduction}

There are many problems related to young people. Among these problems, especially the problems related to substance use and drug addiction, which concern the young generation, are noteworthy (Baskurt, 2012).

Addiction is defined as the continuation of the substance intake despite the physical, mental or social problems that arise during the process of taking a substance to obtain a significant effect, its inability to be released despite the desire to quit, increasing the amount of substance taken to achieve the same effect and the desire to stop the substance (Ministry of Health $(\mathrm{MOH}), 2019)$. When it comes to matter, the object that can be perceived and divided by the senses comes to mind. Substances are objects that cause intoxication in people and disrupts the health of physical and mental life (alcohol, tobacco, heroin, poppy, drugs, etc.), which prevents the mind from performing its activities (Budak, 2000). Substance abuse differs from other health problems with its various features. One of the simple differences that distinguish substance abuse from other disorders (depression, anxiety disorders, etc.) is that starting to use drugs can be considered as a behavior of the person's choice. It is unclear whether this choice is a rational choice. However, this behavior, which initiates the path to addiction later, forms the basis for addressing addiction as a behavioral problem and cognitive and behavioral approaches that have an important place in the treatment (Polat, 2014). Substance abuse that occurs as a deterioration of the individual, social and professional life of the person who shows long-term physiological and psychological dependences on the substance used is substance abuse. In connection with the deterioration of life, failure to fulfill basic responsibilities in work, school or home life, having problems in legal relations with the substance or interpersonal relations, or using the substance despite aggravating the existing problems may indicate substance abuse. However, in order to be able to make this diagnosis, it is necessary to repeat the use of the substance frequently over a long period and to develop a tolerance for the substance taken.

Substance addiction is an important problem since the discovery that addictive substances change a person's mental state and make him/her feel different, even though for a short time (Beyazyürek and Satır, 2000). Addiction is a process that destroys the individual's freedom and autonomy (Doğan, 2001). Substance addiction can be largely defined by behaviors related to searching for and receiving the substance. At the heart of these behaviors are individuals' decision-making processes, such as choosing to take medication for more positive social activity (Stoops and Kearns, 2018). Substance abuse can also be used by addicts to solve psychological problems and meet personal needs. These unhealthy cognitive factors are often effective in applying the substance. Many personality traits such as low self-esteem, individualization, irrational attitudes and beliefs, high tendency to rebel, inability to adapt to conflict and conflict management skills, low self-esteem to group and community, and low self-esteem may be effective in the emergence of these cognitive factors (Gürol, 2008).

The use of addictive substances by adolescents disrupts their social and psychological structures and affects their quality of life and thus becomes one of the most important problems for them (Köknel (1998). Turkish National Monitoring Centre for Drugs and Drugs Addiction (TUBIM), in their study conducted in 2011-2012 with 11812 high school sophomore students reported that 1.5\% of the students demonstrated at least one substance use behavior (Turkish National Monitoring Centre for Drugs and Drugs Addiction (TUBIM), 2012).

The increase in substance use and addiction has become one of the most important public health problems that all societies have to face by overcoming racial and ethnic differences (Dumas et al., 1999). According to the research of the Turkish National Monitoring Centre for Drugs and Drugs Addiction in 2011, the smoking rate in the 15-24 age group was $4.6 \%$, while the rate of alcohol use was found to be $10.4 \%$. According to the data of substance use in the $15-24$ age group is $2.9 \%$. Compared to other age groups, this group is the age range in which substance use is highest (Turkish Statistical Institute (TSI), 2012).

Sports schools as educational institutions in Turkey, depending on the Ministry of Education is an institution that has started training in 2004. These educational institutions provide 4 years of education and training in the field of sports education. In line with their interests, desires and abilities, students are educated to acquire basic knowledge and skills related to sports education and they grow up as successful individuals in their fields. Students are preparing for higher education programs related to sports in these educational institutions. They grow as individuals who contribute to Turkish art, culture and sports and successfully represent their country. In these educational institutions, students are provided with sports disciplines and grow as individuals who adopt the gentlemanliness (Ministry of National Education (MONE), 2019). It is the duty and responsibility of adults to protect the physical and mental health of these young people, who are carriers of societies and societal cultures for the future. Their healthy upbringing is the basic issue of all societies. The study was done in this context, the critical age range representing the sports high school students' attitudes toward the addictive substances in Turkey were examined.

\section{Materials and Method}

In this research, the "quantitative method" was used and the relational survey type was preferred as the research design. Karasar (2014) described the relational screening model as a research model aiming to determine the existence and the degree of co-change between two and more variables.

The study group consisted of 326 students randomly selected from the Elazig Sports High School (145 students), Erzincan Sports High School (104 students) and Malatya Sports High School (77 students). In order to obtain the data from the research group, the validity and reliability study developed by Aksoy (2006) was 
conducted. In this study, Cronbach-Alpha internal consistency coefficient was found to be 0.821 in the validity and reliability study.

As a result of the data obtained from 326 students, first of all, the normality test was performed to determine whether the Attitude toward Addictive Substances Scale fulfills the assumption of normality. As it can be seen in Table 1, the skewness and kurtosis values of the Attitude toward Addictive Substances Scale were found to be between +1.5 and -1.5 and it was determined that the normality was realized. Because, in Tabachnic and Fidell (2007) skewness and kurtosis values in the range of +1.5 to -1.5 stated that the distribution can be interpreted as normal.

Table-1. Result of the normality test of the Attitude toward Addictive Substances Scale

\begin{tabular}{c|c|c|c|c|c}
\hline Scale & $\mathbf{N}$ & $\overline{\mathbf{X}}$ & $\mathbf{S d}$ & Mixture & Corruption \\
\hline Attitude toward addictive substances scale & 326 & 3.032 & 0.681 & {$\left[\begin{array}{c}-0.210 ; \\
0.135]\end{array}\right.$} & $\begin{array}{c}{[0.796 ;} \\
0.269\end{array}$ \\
\hline
\end{tabular}

Afterward, frequency and percentage calculations were made to reveal the distribution of the research group according to individual variables. Independent variables; Sample Independent Sample t-Test den, one of the parametric tests, to assess the level of differentiation according to gender variable; (t-test) was used to determine differentiations according to age, family income and class variables. For the variables of the education level of fathers and mothers of the research group, "Kruskal Wallis Test" was performed, which is one of the nonparametric tests. In the study group, the Kruskal Wallis Test was preferred from non-parametric tests because the educational status of the parents of the students was less than 30. LSD test was used to moderate the differences between the independent variables. The level of statistical significance was accepted as $\mathrm{p}<0.05$.

\section{Results and Interpretation}

In this section, the findings obtained from the opinions of sports high school students receiving sports education are given for the purposes of the research.

Table-2. Results of the t-test according to the genders of the research group.

\begin{tabular}{l|c|c|c|c|c|c}
\hline \multicolumn{1}{c|}{ Scale } & Gender & $\mathbf{N}$ & $\overline{\mathbf{X}}$ & $\mathbf{S d}$ & t-Value & p-Value \\
\hline Attitude toward addictive substances scale & Male & 233 & 2.998 & 0.702 & \multirow{2}{*}{-1.416} & \multirow{2}{*}{0.158} \\
\cline { 2 - 5 } & Female & 93 & 3.116 & 0.621 & & \multirow{2}{*}{ Note: Independent sample T-test, $\mathrm{p}<0.05}$.
\end{tabular}

When the attitudes of sports high school students toward addictive substances were examined, according to gender variable; no statistically significant difference was observed ( $p>0.05)$.

\begin{tabular}{|c|c|c|c|c|c|c|c|}
\hline Scale & Age & $\mathbf{N}$ & $\overline{\mathbf{x}}$ & Sd & $\mathbf{F}$ & p-Value & LSD \\
\hline \multirow{3}{*}{$\begin{array}{l}\text { Attitude toward addictive } \\
\text { substances scale }\end{array}$} & (a) 14-15 age & 106 & 2.899 & 0.602 & \multirow{3}{*}{3.345} & \multirow{3}{*}{$0.036^{*}$} & \multirow{3}{*}{$\begin{array}{l}\mathrm{a}, \mathrm{b} \\
\mathrm{a}, \mathrm{c}\end{array}$} \\
\hline & (b) 16-17 age & 158 & 3.072 & 0.707 & & & \\
\hline & (c) 18-19 age & 62 & 3.156 & 0.715 & & & \\
\hline
\end{tabular}

There was a statistically significant difference between sports high school students' attitudes toward addictive substances, according to the age variable $(\mathrm{p}<0.05)$. The attitudes of the students between the ages of $14-15$ to addictive substances were lower than the students in the other age groups Table 3.

Table 4. ANOVA analysis results according to the monthly income of the family.

\begin{tabular}{|c|c|c|c|c|c|c|}
\hline Scale & onthly income & $\mathbf{N}$ & $\overline{\mathbf{x}}$ & Sd & $\mathbf{F}$ & p-Value \\
\hline \multirow{4}{*}{$\begin{array}{l}\text { Attitude toward addictive substances } \\
\text { scale }\end{array}$} & (a) $0-1500 \mathrm{TL}$ & 78 & 3.053 & 0.581 & \multirow{4}{*}{1.048} & \multirow{4}{*}{0.372} \\
\hline & (b) $1501-3000 \mathrm{TL}$ & 150 & 2.996 & 0.735 & & \\
\hline & (c) $3001-5000 \mathrm{TL}$ & 64 & 2.992 & 0.636 & & \\
\hline & $\begin{array}{l}\text { (d) } 5001 \mathrm{TL} \text { and } \\
\text { above }\end{array}$ & 34 & 3.215 & 0.726 & & \\
\hline
\end{tabular}

Note: One way anova, $\mathrm{p}<0.05$.

Sport high school students' attitudes toward addictive substances did not show a statistically significant difference, according to the monthly income of the family ( $p>0.05)$.

Table-5. Results of ANOVA analysis according to the class levels of the research group.

\begin{tabular}{|c|c|c|c|c|c|c|c|}
\hline Scale & Class level & $\mathbf{N}$ & $\overline{\mathbf{x}}$ & Sd & $\mathbf{F}$ & p-Value & LSD \\
\hline \multirow{4}{*}{$\begin{array}{l}\text { Attitude toward addictive substances } \\
\text { scale }\end{array}$} & (a) 1.Class & 89 & 2.793 & 0.620 & \multirow{4}{*}{5.403} & \multirow{4}{*}{$0.001^{*}$} & \multirow{4}{*}{$\begin{array}{l}a, b \\
a, c \\
a, d\end{array}$} \\
\hline & (b) 2.Class & 77 & 3.165 & 0.681 & & & \\
\hline & (c) 3.Class & 84 & 3.118 & 0.641 & & & \\
\hline & (d) 4.Class & 76 & 3.081 & 0.734 & & & \\
\hline
\end{tabular}

Sport high school students' attitudes toward addictive substances showed a statistically significant difference, according to their level of education $(\mathrm{p}<0.05)$. It was observed that the attitudes of $1^{\text {st }}$ grade students toward addictive substances were lower than that of other grade students Table 5. 
Table-6. The results of the analysis of the Kruskal-Wallis test according to the educational status of the father of the research group.

\begin{tabular}{|c|c|c|c|c|c|c|}
\hline Scale & Education & $\mathbf{N}$ & $\bar{x}_{\text {sira }}$ & Sd & $\mathbf{X}^{2}$ & $\mathbf{p}$ \\
\hline \multirow{5}{*}{$\begin{array}{l}\text { Attitude toward addictive substances } \\
\text { scale }\end{array}$} & (a) Illiterate & 13 & 183.08 & & \multirow{5}{*}{1.563} & \multirow{5}{*}{0.815} \\
\hline & (b) Primary School & 82 & 165.21 & & & \\
\hline & (c) Secondary School & 104 & 161.77 & 3.032 & & \\
\hline & (d) High School & 100 & 165.93 & & & \\
\hline & (e) University & 27 & 146.56 & & & \\
\hline
\end{tabular}

Note: Independent samples (Kruskal-Wallis H), p<0.05.

There was no statistically significant difference between the attitudes of sports high school students toward the addictive items regarding their fathers' educational level $(\mathrm{p}>0.05)$.

Table-7. The results of the analysis of the Kruskal-Wallis test according to the educational status variable of the mother of the research group.

\begin{tabular}{|c|c|c|c|c|c|c|}
\hline \multicolumn{2}{|l|}{ Scale } & $\mathbf{N}$ & $\overline{\mathbf{X}}_{\mathrm{rank}}$ & Sd & $\mathbf{X}^{2}$ & $\mathbf{P}$ \\
\hline \multirow{5}{*}{$\begin{array}{l}\text { Attitude toward addictive substances } \\
\text { scale }\end{array}$} & (a) Illiterate & 36 & 156.90 & & \multirow{5}{*}{$\begin{array}{r}0.3 \\
60\end{array}$} & \multirow{5}{*}{0.986} \\
\hline & (b) Primary School & 121 & 166.33 & & & \\
\hline & (c) Secondary School & 94 & 163.34 & 0.681 & & \\
\hline & (d) High School & 54 & 160.61 & & & \\
\hline & (e) University & 21 & 166.64 & & & \\
\hline
\end{tabular}

Note: Independent samples (Kruskal-Wallis H), p<0.05.

There was no statistically significant difference between the attitudes of mothers of sports high school students toward the addictive items regarding their educational status $(\mathrm{p}>0.05)$.

\section{Discussion and Conclusion}

The findings obtained as a result of the analyzes carried out within the scope of the objectives of the research are evaluated as follows:

There was no significant difference between men and women according to the gender variable of the study group Table 2. It can be said that male and female students are undecided about their attitudes toward addictive substances. When other studies were examined, the following conclusions were reached: Turhan et al. (2011) reported that male students had a higher incidence of smoking, alcohol and drug use compared to female students. Yalçın et al. (2009) in 2119 students, the prevalence of substance use was found to be 4.9 times higher than male students. In addition, in another study conducted on university students, a study on the 12-month prevalence of nicotine, alcohol and substance addiction revealed that all students diagnosed with alcohol dependence were male (Kaya and Cilli, 2002). In their study, Tansel (2017) found no significant difference in the attitudes of male and female students toward addictive substances.

A significant difference was found in the age variable in the study group. This difference was found to be between the ages of 14-15 and other groups. The attitudes of the group in the 14-15 age group were less than the other groups Table 3. The reason for this is thought to be related to the fact that students in this age group are at the beginning of adolescence. As age progresses, it can be said that the attitude toward addictive substances has changed negatively in high school students. When the other studies were examined, it was seen that the same results were reached (Aksoy, 2006; Turhan et al., 2011).

In the study group, the attitudes of the family toward addictive substances did not differ statistically according to the monthly income level Table 4. Ulukoca et al. (2013) the same results were reached.

The attitudes of the study group toward addictive substances showed statistically significant differences according to the level of education they received Table 5. It was found that the attitudes of 1 st grade students toward addictive substances were lower than the students in the other grade. It can be said that the attitudes of the students increased as the grade levels increased. In the study of Erdamar and Kurupinar (2014) similar results have been reached with these results.

There was no statistically significant difference between the fathers of the research group according to their educational level Table 6 . When the educational status of the mother was examined, the same results were obtained Table 7. Coşkun (2008) concluded that the education level of the father was effective in substance use. Ulukoca et al. (2013) did not reach a significant difference. Education levels of parents do not affect students' smoking behavior.

According to the results of the study, the prevalence of substance use among young people seems to be a serious problem. Young people who use any of these types of matter with curiosity or a perception that nothing happens to me find themselves in this swamp. This addiction leads to personality disorders such as being suicidal, aggression, anger, nervous breakdown and restlessness. Young people who do not want to fall into this situation, despite all these financial and medical difficulties continue to consume substances. It is of utmost importance to protect the future of our country in general and the health of young people in particular by taking preventive measures. According to the results of the study, it was concluded that male and female students' attitudes toward addiction increased as their age and grade levels progressed negatively. In order to prevent this picture, more attention should be paid to education-oriented prevention activities and the number of educational activities such as psychological support and health programs for young people should be increased by guidance counselors and psychological counselors. Informative training should be provided not only for students, but also for parents, such as adolescent psychology and communication with young people, and then they should be actively involved in this preventive program. 


\section{References}

Aksoy, K., 2006. High school students' attitudes towards addictive substances and investigation of the variables affecting these attitudes (Malatya city sample), İnönü University, Malatya; Institute of Social Sciences.

Baskurt, I., 2012. Youth, substance abuse and ways of prevention (A Psycho-Social Approach) (trans .: Youth, Substance Abuse and Ways of Prevention)(8).

Beyazyürek, M. and T.T. Satır, 2000. Matter use disorders (trans.: Substance use disorders). The World of Psychiatry, 4: 50-56.

Budak, S., 2000. Dictionary of psychology (trans.: Psychology dictionary). Ankara: Science and Art Publications.

Coşkun, F., 2008. Gaziantep University Center Campus-The use of alcohol and drugs in Ba Students: Gaziantep University Faculty of Medicine Specialty Thesis.

Doğan, Y.B., 2001. Substance use and addiction (trans.: Substance use and addiction). Family and Society, 1(4): 79-86.

Dumas, J.E., D. Rollock, R.J. Prinz, H. Hops and E.A. Blechman, 1999. Cultural sensitivity: Problems and solutions in applied and preventive intervention. Applied and Preventive Psychology, 8(3): 175-196.Available at: https://doi.org/10.1016/s0962-1849(05)80076-9.

Erdamar, G. and A. Kurupınar, 2014. The habit of drug addiction and prevalence among the secondary school students: Sample of Bartın city. Journal of Social Sciences, 16(1): 65-84.Available at: https://doi.org/10.5578/jss.752 1.

Gürol, D.T., 2008. Adolescents at risk from substance addiction. Istanbul University Cerrahpasa Faculty of Medicine Continuing Medical Education Activities, Adolescent Health II Symposium Series, 63: 65-68.

Karasar, N., 2014. Scientific research method: Concepts principles techniques. Ankara: Nobel Academy Publishing.

Kaya, N. and A.S. Cilli, 2002. 12-month prevalence of nicotine, alcohol and substance abuse among university students. Journal of Addiction, 3(2): 91-97.

Köknel, Ö., 1998. Addiction "alcohol and substance addiction” (trans.: Addiction "alcohol and substance addiction”). Istanbul: Gelişim Publications.

Ministry of Health (MOH), 2019. Republic of Turkey. Available from http://www.istanbulsaglik.gov.tr/w/sb/per/belge/bagimlilik.pdf [Accessed 19 November 2019].

Ministry of National Education (MONE), 2019. Republic of Turkey. Available from http://mebk 12.meb.gov.tr [Accessed 17 October 2019].

Polat, G., 2014. Social work profession in the treatment of drug addiction. Okmeydanı Medical Journal, 30(2): 143-148.

Stoops, W.W. and D.N. Kearns, 2018. Decision-making in addiction: Current knowledge, clinical İmplications and future directions. Pharmacol Biochem Behaviour, 164: 1-3.

Tabachnic, B.G. and L.S. Fidell, 2007. Using multivariate statistics. Allyn\&Bacon, Pearson Educatin.

Tansel, B., 2017. Examining high school students attitudes towards addictive substances. Hitit University Journal of Social Sciences Institute, Year, 10(2): 1453-1472.

Turhan, E., T. Inandi, C. Ozer and S. Akoglu, 2011. Substance use, violence among university students and their some psychological characteristics. Turk Journal Public Health, 9(1).

Turkish National Monitoring Centre for Drugs and Drugs Addiction (TUBIM), 2012. Available from http://www.sck.gov.tr/oecd/2012\%20T\%C3\%BCrkiye\%20Uyu\%C5\%9Fturucu\%20Raporu.pdf [Accessed 17 October 2019].

Turkish Statistical Institute (TSI), 2012. Available from http://www.turkstat.gov.tr/ [Accessed 16 October 2019].

Ulukoca, N., S. Gokgoz and A. Karakoc, 2013. Prevalence of tobacco, alcohol, and substance use in Kirklareli University students. Firat Medical Journal, 18(4): 230-234.

Yalçın, M., A. Eşsizoğlu, H. Akkoç, A. Yaşan and F. Gürgen, 2009. Risk factors associated with substance use among dicle university students. Journal of Clinical Psychiatry, 12(3): 125-133. 